\title{
Tsafon
}

Revue d'études juives du Nord

$73 \mid 2017$

Connaissance de la Shoah : témoignages, enseignements, visites

\section{Henri Minczeles (1926-2017)}

Historien, journaliste, militant, conférencier, animateur radio, dirigeant communautaire

\section{Michèle Tauber}

\section{OpenEdition}

\section{Journals}

Édition électronique

URL : https://journals.openedition.org/tsafon/310

DOI : $10.4000 /$ tsafon.310

ISSN : 2609-6420

Éditeur

Association Jean-Marie Delmaire

Édition imprimée

Date de publication : 1 juin 2017

Pagination : 169-174

ISSN : $1149-6630$

Référence électronique

Michèle Tauber, « Henri Minczeles (1926-2017) », Tsafon [En ligne], 73 | 2017, mis en ligne le 31 mai 2018, consulté le 24 juin 2021. URL : http://journals.openedition.org/tsafon/310 ; DOI : https://doi.org/ 10.4000/tsafon.310 


\section{Hommage}

\section{Henri Minczeles (1926-2017)}

\section{Historien, journaliste, militant, conférencier, animateur radio, dirigeant communautaire}

\section{Michèle Tauber*}

Né à Paris en 1926 dans une famille juive polonaise, Henri Minczeles connaît une enfance heureuse du côté de la Porte de Clignancourt, mais son adolescence est douloureusement marquée par l'arrestation de son père le 14 mai 1941 lors de la rafle du « billet vert », suivie de sa déportation sans retour à Auschwitz le 17 juillet 1942, par le convoi 6. Henri était alors âgé de 16 ans, son frère Roger, lui, était âgé de 10 ans et demi. Henri gardait pieusement la dernière lettre écrite par son père à sa mère avant son départ pour Auschwitz, dans laquelle il affichait un certain optimisme: "Je pars aujourd'hui même. Peut-être nous reverrons-nous en Pologne? Ne crains rien on ne tuera pas tant de monde. Veille sur les enfants... Je te prie de ne pas pleurer sur notre sort. Sois courageuse. Nous sommes encore jeunes. Je t'embrasse bien fort avec les enfants...»".

Après avoir échappé avec sa mère et son frère à la rafle du 16 juillet 1942, Henri Minczeles part dans un sanatorium de la banlieue parisienne du 13 août 1942 jusqu'au 17 juin 1943. Il revient à Paris et demeure clandestinement avec de faux-papiers. Il devient ensuite

\footnotetext{
* Université Sorbonne nouvelle, Paris 3.
} 
spécialiste en confection de fausses cartes d'identité et tickets d'alimentation.

En octobre 1943, il trouve un travail dans une entreprise de décoration de cadres. Activement engagé dans la Résistance à Libé Nord, il participe à la libération de Paris le 25 août. Inscrit aux jeunesses socialistes, il fonde la $19^{\mathrm{e}}$ section de Paris des Jeunesses socialistes. Puis il adhère au Bund ${ }^{1}$ et rejoint le centre Medem-Arbeter Ring, tout en suivant les cours de formation des journalistes. En 1949, il épouse Léa Radacz: ils auront deux enfants, quatre petits-enfants et Henri aura le bonheur de connaître Louise, son arrière-petite-fille.

Après la guerre, Henri Minczeles travaille dans une entreprise textile spécialisée dans le tricot. Suite à la fermeture de cette entreprise, il décide de reprendre ses études interrompues en 1942 et s'inscrit en septembre 1984 à l'École des Hautes Études en Sciences Sociales (EHESS). En 1985, il présente au terme de son premier cycle «Les origines du mouvement ouvrier juif, 1870-1897». Officiellement retraité en 1986, il prépare et obtient le diplôme d'études approfondies (DEA) sur Vilna, Wilno, Vilnius, la Jérusalem de Lituanie, 1918-1940 puis, le 19 mars 1991, un doctorat d'histoire sur le même thème, avec les félicitations du jury.

Dès sa jeunesse, Henri Minczeles participe activement au mouvement bundiste dont il devient une figure incontournable. Très attaché au yiddish et à sa culture, il présidera plus tard le Cercle amical Wladimir Medem - Arbeter Ring.

Son engagement communautaire s'exprime aussi à travers ses convictions politiques et laïques en participant à la création du Club laïque de l'enfance juive (CLEJ), une colonie juive laïque toujours en activité à Corvol-l'Orgeuilleux dans la Nièvre.

En 2000, Henri adhère à l'Association pour la mémoire des enfants juifs déportés du XVIII ${ }^{\mathrm{e}}$ arrondissement. Il sera délégué au $\mathrm{CRIF}^{2}$ de 1979 à 2001 puis à la commission du souvenir du CRIF. Henri Minczeles était aussi un militant de l'Association des Fils et Filles des Déportés Juifs de France de Serge Klarsfleld. Dans l'ouvrage consacré au «Convoi 6 » pour la mémoire de son père Charles Szepsel Minczeles, il écrit :

\footnotetext{
${ }^{1}$ Bund: Algemeyner yidisher arbeter bund in Litè, Poyln un Rusland / Union des travailleurs de Lituanie, Pologne et Russie, fondée en 1897 par Wladimir Medem.

${ }^{2}$ CRIF : Conseil représentatif des institutions juives de France.
} 
Hitler est responsable de mon retour au judaïsme. C'est la raison pour laquelle je suis depuis plus d'un demi-siècle un militant de la mémoire, un chien de garde du souvenir. Je l'ai exprimé dans de nombreuses études et articles à la radio. J'ai écrit des ouvrages consacrés au judaïsme, à son histoire événementielle et à diverses idéologies et doctrines de la judaïcité. J'assiste depuis 1946 à la commémoration du soulèvement du ghetto de Varsovie. J'ai incité mes enfants et mes petits-enfants à venir à cette manifestation du souvenir. Le reste est silence.

Henri Minczeles a consacré ses travaux de recherche à un monde qu'il connaissait : la yiddishkeit ${ }^{3}$ polonaise et a réussi à montrer au public francophone les particularités de ce mouvement ouvrier juif (parti politique, syndicat, coopérative, club de sport, écoles...) ainsi que son originalité: bien que marxiste, le Bund revendiquait l'autonomie culturelle pour les Juifs, ce qui a fait de ce mouvement un grand défenseur du yiddish.

Henri Minczeles est fortement influencé par les conceptions de l'historien juif russe Shim'on Dubnow pour lequel la survie future des Juifs en tant que nation dépend de leur force culturelle et spirituelle et de leur autonomie dans la diaspora. "Le peuple juif demeure vivant et créateur, écrit-il, grâce à ses innombrables combats sur les champs de bataille de l'esprit ».

Henri Minczeles est l'auteur de plusieurs ouvrages importants sur le judaïsme ashkénaze :

- Vilna, Wilno, Vilnius, la Jérusalem de Lituanie, Paris, La Découverte, 1993. Réédité en 2000, puis traduit en lituanien.

- Histoire générale du Bund, un mouvement révolutionnaire juif, Paris, Austral, 1995. Réédité en 1999 à Paris, chez Denoël.

- Lituanie juive, message d'un monde englouti, en collaboration avec Yves Plasseraud, Paris, Éd. Autrement, 1996.

- Yiddishland, en collaboration avec Gérard Silvain, Paris, Éd. Hazan, 1999.

- Une histoire des Juifs de Pologne. Religion, culture, politique, Paris, La

Découverte, 2006. Livre de Poche, 2011. En cours de traduction en polonais.

\footnotetext{
${ }^{3}$ Yiddishkeit : langue et culture du monde juif d'Europe centrale et orientale jusqu'en 1939.
} 
- Les Litvaks, l'héritage universel d'un monde juif disparu, en collaboration avec Yves Plasseraud et Suzanne Pourchier, Paris, La Découverte, 2008.

- Le mouvement ouvrier juif. Récit des origines, Paris, Éd. Syllepse, 2010 .

Traduction :

- Ma vie, de Vladimir Medem. Traduit du yiddish avec Aby Wieviorka. Paris, Éd. Honoré Champion, 1999.

Il est également lauréat de nombreux prix et récompenses : Prix Mémoire de la Shoah, fondation Jacob Buchman, Prix Emil Domberger du B'nai Brith décerné à Jérusalem, Prix Idel Korman pour le yiddish, Prix Cukierman pour le yiddish, Médaille d'Argent de la Ville de Paris, Chevalier de l'Ordre National du Mérite, Médaille Grand Argent de la Ville de Paris, Croix d'Officier de l'Ordre National du Mérite lituanien.

Henri Minczeles a préfacé une vingtaine de livres, a donné des conférences et des cours divers sur le judaïsme polonais, israélien, américain au Centre Medem, à l'EHESS, au Centre Universitaire Élie Wiesel et dans de nombreuses institutions juives et non juives. Il est intervenu dans de nombreux colloques et il est le principal organisateur à Paris des manifestations du Centenaire du Bund en 1997. Il a également participé à diverses expositions sur Vilnius, Lodz, la presse yiddish, le Bund ou encore, en 2006 : "Les enfants juifs du XVIII ${ }^{\mathrm{e}}$ arrondissement sous l'occupation ».

Je souhaite exprimer personnellement toute mon admiration et mon amitié pour Henri Minczeles que je connaissais depuis 1983. Nous avons eu à maintes reprises l'occasion de parler littérature : Henri était un grand lecteur et il avait une passion pour la littérature française qu'il connaissait à merveille. J'ai en mémoire sa passion pour Roger Martin du Gard dont il me citait des passages par cœur. Personnage enthousiaste et chaleureux, Henri demeure vivant pour tous ceux qui l'ont connu et aimé.

L'équipe de Tsafon conserve le souvenir chaleureux de Henri Minczeles et dit sa tristesse à sa famille. 
Henri Minczeles

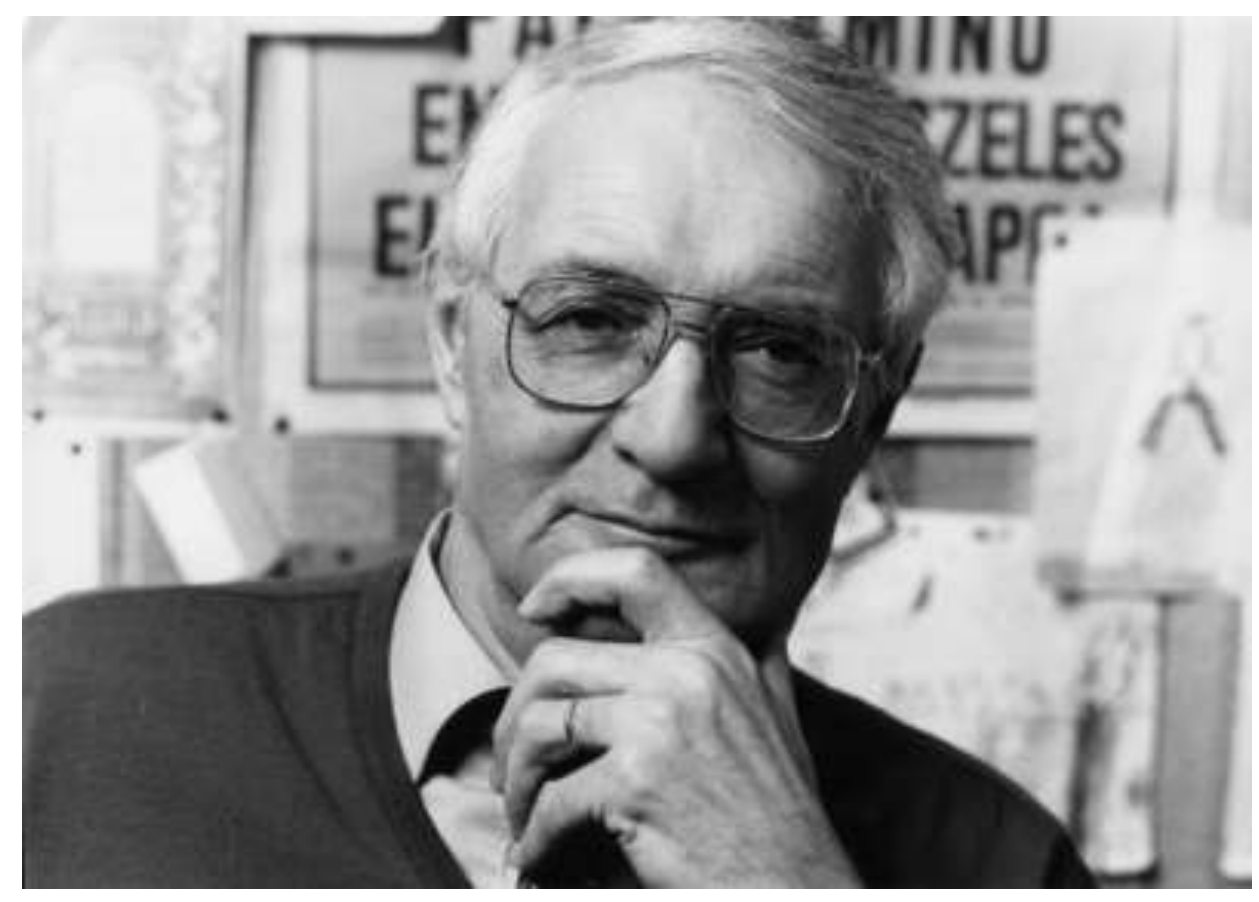

(archives familiales) 
Dernière lettre du père de Henri Minczeles à sa mère avant son départ pour Auschwitz

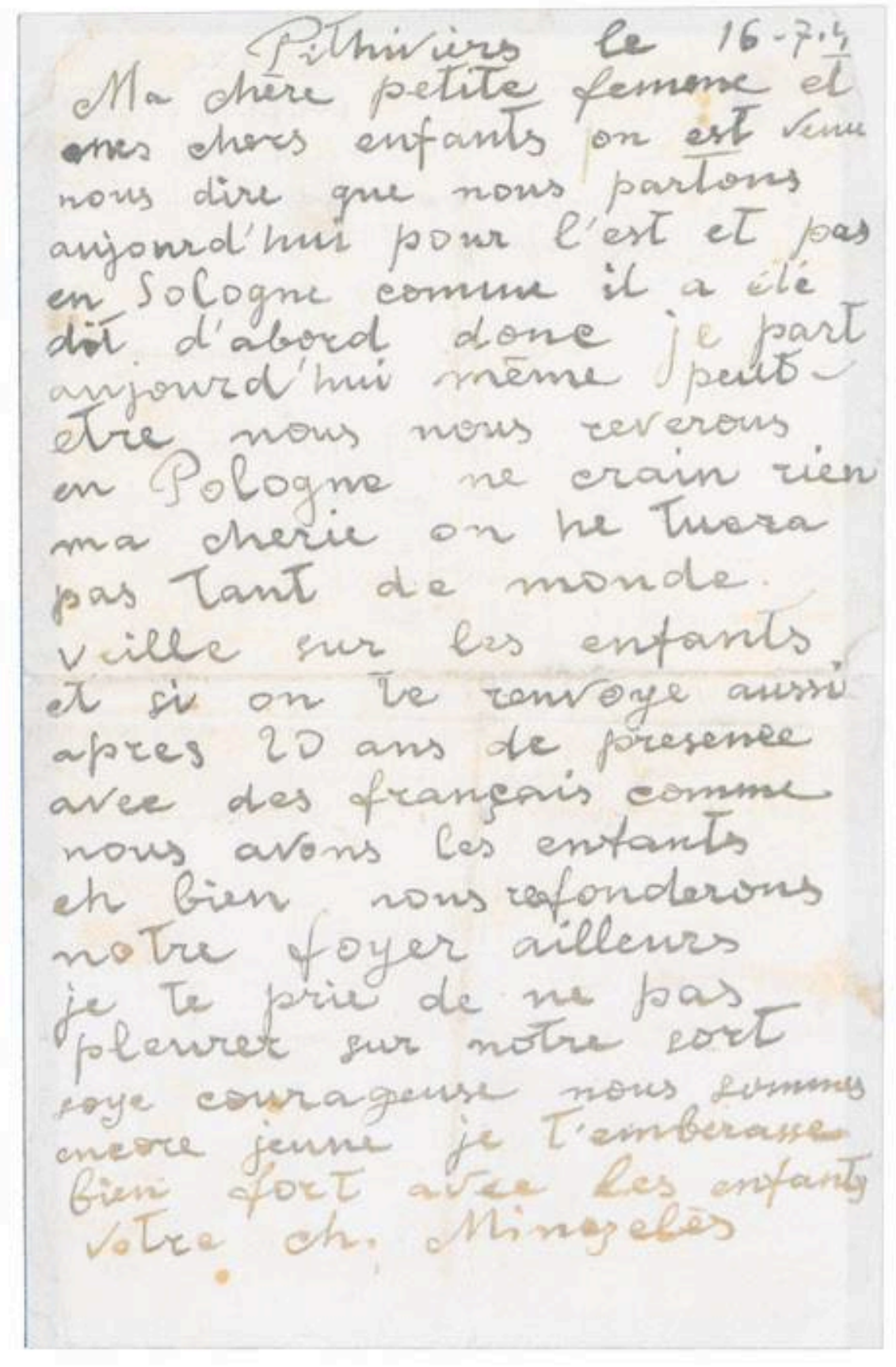

(archives familiales) 